\title{
Complications after Body Contouring Surgery in Post- Bariatric Patients: The Importance of a Stable Weight Close to Normal
}

\author{
Eva S.J. van der Beek ${ }^{a} \quad$ Aebele Mink van der Molen ${ }^{a, b} \quad$ Bert van Ramshorst ${ }^{c}$ \\ a Department of Plastic and Reconstructive Surgery, St. Antonius Hospital, Nieuwegein, \\ ${ }^{\mathrm{b}}$ Department of Plastic and Reconstructive Surgery, University Medical Centre Utrecht, \\ ${ }^{\mathrm{c}}$ Department of Surgery, St. Antonius Hospital, Nieuwegein, the Netherlands
}

\section{Keywords}

Obesity · Body contouring surgery · Complications

\section{Summary}

Objective: Body contouring surgery is in high demand following the increase in bariatric surgery. Massive weight loss leads to an excess of lax, overstretched skin causing physical and psychosocial discomfort. Plastic surgical procedures can give rise to an improvement in quality of life, but the relative high complication rate could negatively affect these potential gains. The purpose of this study is to identify predictors of complications in order to optimize outcomes in this patient population. Methods: Out of a group of 465 post-bariatric patients, 61 patients underwent body contouring surgery following massive weight loss. A total of 43 respondents were reviewed retrospectively for demographic data, pre- and post-operative weight status and co-morbidities. Medical complications were categorized according to the modified Clavien classification. All cases were analyzed for risk factors. Results: A stable weight over a period of at least 3 months prior to body contouring surgery is associated with a significant lower complication rate (odds ratio $0.24 ; \mathrm{Cl} 0.07-0.79$ ) and the percentage excess weight loss (odds ratio $0.96 ; 95 \% \mathrm{Cl} 0.92-1.00$ ) was an independent predictor for the occurrence of complications. The overall complication rate was $27.9 \%$ with a major complication rate of $8.8 \%$. Most frequent procedures were abdominoplasty (61\%) and breast reduction/ mammapexy (25\%). Conclusion: This study emphasizes the importance to strive for a stable weight close to normal before surgery to minimize the risk of complications. The positive effects of the long-term results of bariatric surgery tolerate the relative high complications rate. Careful pre-operative planning and patient selection are essential to optimize the results of body contouring surgery of post-bariatric patients.

\section{Introduction}

With the worldwide increase of obesity, bariatric surgery is expanding proportionally. Surgery is the only treatment resulting in long-term, sustained weight loss and decrease in co-morbidities [1] but also comes along with unsightly excessive and lax skin. Following bariatric procedures an increasing number of patients is seeking body contouring surgery. Although these operations are associated with in an increase in quality of life and a high patient satisfaction, the relative high complication rates [2-4], negatively affect these potential gains.

Controversy exists in the literature about the predictors of poor outcome [2, 3, 5]. Pre-body contouring BMI [2-4, 6, 7], percentage excessive weight loss [5], smoking [8-10], diabetes mellitus and/or hypertension [8], nutritional deficiency [11] ASA classification [5], total amount of removed tissue [4, 7], intra-operation time, multiple procedures, maximum BMI and change in BMI from maximum to current BMI [12] are mentioned variable as risk factors.

In this study we analyzed the results of body contouring surgery in weight loss surgery patients to identify predictors of complications in order to optimize patient selection and appropriate timing of surgery. Factors influencing patient satisfaction with the outcome of body contouring surgery were analyzed.

\section{KARGER}

Fax +497614520714

Information@Karger.de

www.karger.com (c) 2011 S. Karger GmbH, Freiburg

1662-4025/11/0041-0061\$38.00/0

Accessible online at:

www.karger.com/ofa
Bert van Ramshorst MD, PhD

Department of Surgery, St. Antonius Hospital

Koekoekslaan 1,3435 CM Nieuwegein, the Netherlands

Tel +31 30 60-99111, Fax +-36578

b.ramshorst@antoniusziekenhuis.n 


\section{Patients and Methods}

\section{Patients}

A total of 465 patients underwent weight loss surgery at the St Antonius Hospital in Nieuwegein over a 10-year time period (November 1995 to April 2005). Of these patients 61 underwent body contouring surgery in the same hospital following massive weight loss. Patients were included in the study if adequate documentation was available. Patients were referred to the Department of Plastic and Reconstructive Surgery with a time interval of at least 2 years following the bariatric procedure if they had complaints of redundant skin and weight has stabilized.

\section{Data Collection}

A retrospective chart review was performed. The following data and variables were collected: patient's age, sex, BMI at the time of bariatric and body contouring surgery, the percentage of excess weight loss, current BMI, weight of resected tissue, smoking status, co-morbidity and medicine use at the time of body contouring surgery, and the type of bariatric and body contouring procedures. Weight changes in the 3 months immediately prior to the reconstructive surgery were recorded.

\section{Outcome}

Complications and interventions associated with each complication were recorded. Complications were categorized into 5 grades according to the modified Clavien classification (table 1) [13, 14]. This is a therapy-oriented grading system and differentiates in five degrees of severity upon the intention to treat. Patient satisfaction was analyzed by asking patients to what extent they were satisfied with the outcome of the reconstructive surgery. The results were expressed on a scale ranging from 1 (very satisfied) to 4 (very dissatisfied).

\section{Statistical Analyses}

Statistical analysis was performed using SPSS for Windows version 12.0.1 (SPSS Inc, Chicago, IL, USA). Uni- and multivariate logistic regressions were used to define odds ratios for potential risk factors for complications. Regression analysis was performed to determine factors influencing patient satisfaction. Student's t-test and multivariate analysis were used for parametric variables, nominal variables were analyzed by Pearson's chi-square test. A two-sided $\mathrm{p}$ value $<0.05$ was considered statistically significant.

\section{Results}

Of the 61 patients who underwent body contouring surgery, a total of $43(70.5 \%)$ patients ( 2 males, 41 female) could be included in the study (table 2). 18 patients were excluded: 7 because of insufficient documentation, 3 patients did not want to participate, and 8 patients were lost to follow-up.

The mean age of the patients was 41.5 years (range 23-60 years). The mean weight before the primary bariatric procedure was $138.2 \mathrm{~kg}(106-230 \mathrm{~kg})$ with a mean BMI of $48.2 \mathrm{~kg} / \mathrm{m}^{2}$ $\left(35.8-79.5 \mathrm{~kg} / \mathrm{m}^{2}\right) .40$ patients $(93 \%)$ underwent laparoscopic gastric banding (LAGB), and 3 patients underwent gastric bypass surgery as a primary procedure. Due to unsatisfactory results or band-related problems, 11 of the 40 LAGB patients underwent gastric bypass surgery as a redo-operation.

The patients experienced a mean excess weight loss of $70.7 \%$ at a mean interval of 42.1 months (8-110 months) between their primary bariatric procedure and body contouring surgery, resulting in a mean weight of $86.9 \mathrm{~kg}(57.0-177.0 \mathrm{~kg})$ and a BMI of $30.7 \mathrm{~kg} / \mathrm{m}^{2}\left(21.5-65.0 \mathrm{~kg} / \mathrm{m}^{2}\right)$ at the time of body contouring surgery.

A total of 68 body contouring procedures were performed in 43 patients; 24 patients $(55.8 \%)$ underwent 1 operation, 13 $(30.2 \%)$ underwent 2 operations, and $6(14 \%)$ of the patients underwent 3 operations. Almost all (94.1\%) operations were single procedures. Table 3 summarizes the procedures performed. Most patients had an abdominoplasty (61\%) or breast reduction/mammapexy (25\%). In $60.3 \%$ of the body contouring procedures, patients had a stable weight at least 3 months before surgery.

The overall complication rate was $27.9 \%$. Complication rates according to the modified Clavien classification were grade $0: 72.1 \%$, grade $1: 19.1 \%$, grade $2: 4.4 \%$, grade $3 \mathrm{~b}$ : $4.4 \%$. There was no post-operative mortality (table 4). The operation most frequently associated with complications was abdominoplasty; $78.9 \%$ of all complications and all major
Table 1. Clavien classification of surgical complications

\begin{tabular}{|c|c|}
\hline Grade & Definition \\
\hline 1 & $\begin{array}{l}\text { any deviation from the normal postoperative course without the need for pharma- } \\
\text { cological treatment or surgical, endoscopic, and radiological interventions* }\end{array}$ \\
\hline 2 & $\begin{array}{l}\text { requiring pharmacological treatment with drugs other than such allowed for grade } \\
\text { complications. (blood transfusions and total parenteral nutrition are also included) }\end{array}$ \\
\hline 3 & requiring surgical, endoscopic or radiological intervention \\
\hline $3 \mathrm{a}$ & intervention not under general anesthesia \\
\hline $3 b$ & intervention under general anesthesia \\
\hline 4 & life-threatening complication (requiring intensive care management) \\
\hline $4 \mathrm{a}$ & single organ dysfunction \\
\hline $4 \mathrm{~b}$ & multiorgan dysfunction \\
\hline 5 & death of a patient \\
\hline
\end{tabular}


Table 2. Patient characteristics

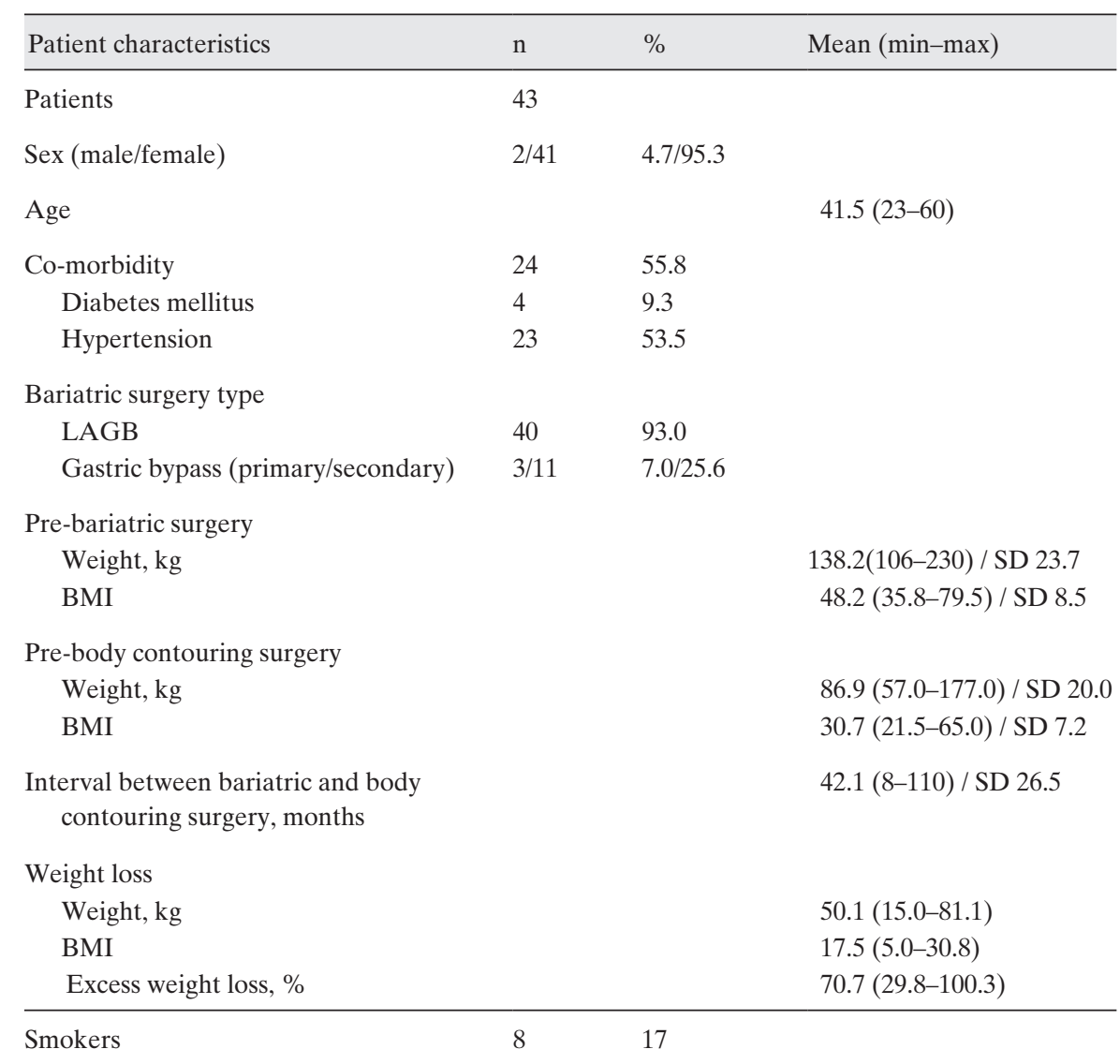

Table 3. Type of body contouring surgery

\begin{tabular}{llc}
\hline Body contouring procedure & $\begin{array}{l}\text { Total amount } \\
\text { performed }\end{array}$ & $\begin{array}{l}\text { \% of patients undergoing } \\
\text { procedure }\end{array}$ \\
\hline Abdominoplasty & 38 & 55.9 \\
Breast augmentation/reduction & 15 & 22.1 \\
Liposuction legs & 3 & 4.4 \\
Dermolipectomy legs & 4 & 5.9 \\
Dermolipectomy arms & 1 & 1.5 \\
Dogear correction & 3 & 4.4 \\
Abdominoplasty + breast reduction & 2 & 2.9 \\
Abdominoplasty + liposuction tights & 1 & 1.5 \\
Dermolipectomy legs + dogear correction & 1 & 1.5 \\
Total & 68 & 100 \\
\hline
\end{tabular}

complications (grade 3b) followed an abdominoplasty. Three patients had a complication which required operative management because of hemorrhage.

Patients with a complicated body contouring procedure had a significantly higher BMI than patients who had an uncomplicated procedure ( 33.5 vs. $28.7 \mathrm{~kg} / \mathrm{m}^{2} ; \mathrm{p}<0.005,95 \%$ CI $\left.0.2-9.3 \mathrm{~kg} / \mathrm{m}^{2}\right)$. The mean difference was $13.8 \mathrm{~kg}(95 \%$ CI $1.0-26.6 \mathrm{~kg})$.

The patients were subdivided into 4 categories based on BMI: normal weight $\left(18.5-24.9 \mathrm{~kg} / \mathrm{m}^{2}\right)$, overweight $(25-29.9$ $\left.\mathrm{kg} / \mathrm{m}^{2}\right)$, obese $\left(30.0-39.9 \mathrm{~kg} / \mathrm{m}^{2}\right)$ and morbidly obese $(>40 \mathrm{~kg} /$ $\mathrm{m}^{2}$ ) (fig. 1). There was a linear relationship between weight status and complication rate. Obese $\left(B M I>30 \mathrm{~kg} / \mathrm{m}^{2}\right)$ patients had a significantly increased complication rate when compared to non-obese (BMI $<30 \mathrm{~kg} / \mathrm{m}^{2}$ ) patients (42.3 vs. $19.5 \% ; \mathrm{p}<0.05)$.

\section{Risk Factor Analysis}

Univariate analysis was performed to identify risk factors for the occurrence of complications (table 5). The BMI at the time of body contouring surgery (odds ratio 1.14 ; $95 \%$ CI 1.01-1.28) and percentage of excess weight loss (odds ratio 0.96 ; $95 \%$ CI $0.93-0.96$ ) were highly significant parameters as predictors of complications. Furthermore, a stable weight 
Table 4. Classification of surgical complications according to the modified Clavien classification

\begin{tabular}{llll}
\hline Grade & Type of complication & Amount (\%) & Total (\%) \\
\hline 1 & Seroma & $10(14.7 \%)$ & $13(19.1 \%)$ \\
& Minor infection & $3(4.4 \%)$ & \\
2 & Deep infection & $3(4.4 \%)$ & $3(4.4 \%)$ \\
3 & Hematoma & $3(4.4 \%)$ & $3(4.4 \%)$ \\
\hline
\end{tabular}

Table 5. Univariate analysis testing the effect of each variable on the occurrence of any complication

\begin{tabular}{lll}
\hline Variable & Odds ratio $(95 \% \mathrm{CI})$ & $\mathrm{p}$ value \\
\hline Age & $1.03(0.98-1.09)$ & 0.247 \\
Gender & $2.67(0.16-44.91)$ & 0.496 \\
Prior weight loss surgery & $2.02(0.64-6.36)$ & 0.232 \\
BMI & $1.14(1.01-1.28)$ & 0.029 \\
\% Excess weight loss & $0.96(0.93-0.96)$ & 0.027 \\
$\quad$ Morbid) obesity & $3.03(1.01-9.05)$ & 0.048 \\
$\quad\left(B M I>30 \mathrm{~kg} / \mathrm{m}^{2}\right)$ & & \\
Smoker & $0.96(0.26-3.54)$ & 0.953 \\
Hypertension & $0.81(0.25-2.66)$ & 0.727 \\
Diabetes & $0.85(0.08-8.74)$ & 0.893 \\
Stable weight $>3$ months & $0.29(0.09-0.87)$ & 0.028 \\
Weight resected tissue & $1.00(1.00-1.00)$ & 0.111 \\
\hline
\end{tabular}

over a period of at least 3 months prior to body contouring surgery results in significant less complications (odds ratio 0.29; 95\% CI 0.09-0.87). The total cohort was subdivided based on BMI into two categories: obese $\left(\mathrm{BMI}>30 \mathrm{~kg} / \mathrm{m}^{2}\right.$ ) and non-obese $\left(\mathrm{BMI}<30 \mathrm{~kg} / \mathrm{m}^{2}\right)$. A significant increase in complications was seen in obese patients (odds ratio 3.03; 95\% CI 1.01-9.05). All other variables failed to predict an increased risk for complications to occur.

Following univariate analysis, multiple logistic regression was performed to identify independent predictors of complications. A stable weight over a period of at least 3 months prior to body contouring surgery (odds ratio 0.24 ; $95 \%$ CI $0.07-0.79$ ) is an independent predictor for a lower complication rate, and the percentage excess weight loss (odds ratio 0.96; 95\% CI 0.92-1.00) was a significant predictor of complications.

\section{Patient Satisfaction}

$67 \%$ of the patients were satisfied with the overall result of the operation and $72.1 \%$ with the scars in particular. The occurrence of post-operative complications did not influence patient satisfaction (satisfaction score 2.3 vs. 2.5). Only weight increase after body contouring surgery was significantly associated with patient satisfaction: patients with a stable weight after the operation were significantly more satisfied than those with an increase in body weight (satisfaction score 1.9 vs. $2.6 ; \mathrm{p}<0.05$ ). All other factors (number of operations, type of operation, hospital stay) failed to show any influence on patients' satisfaction.

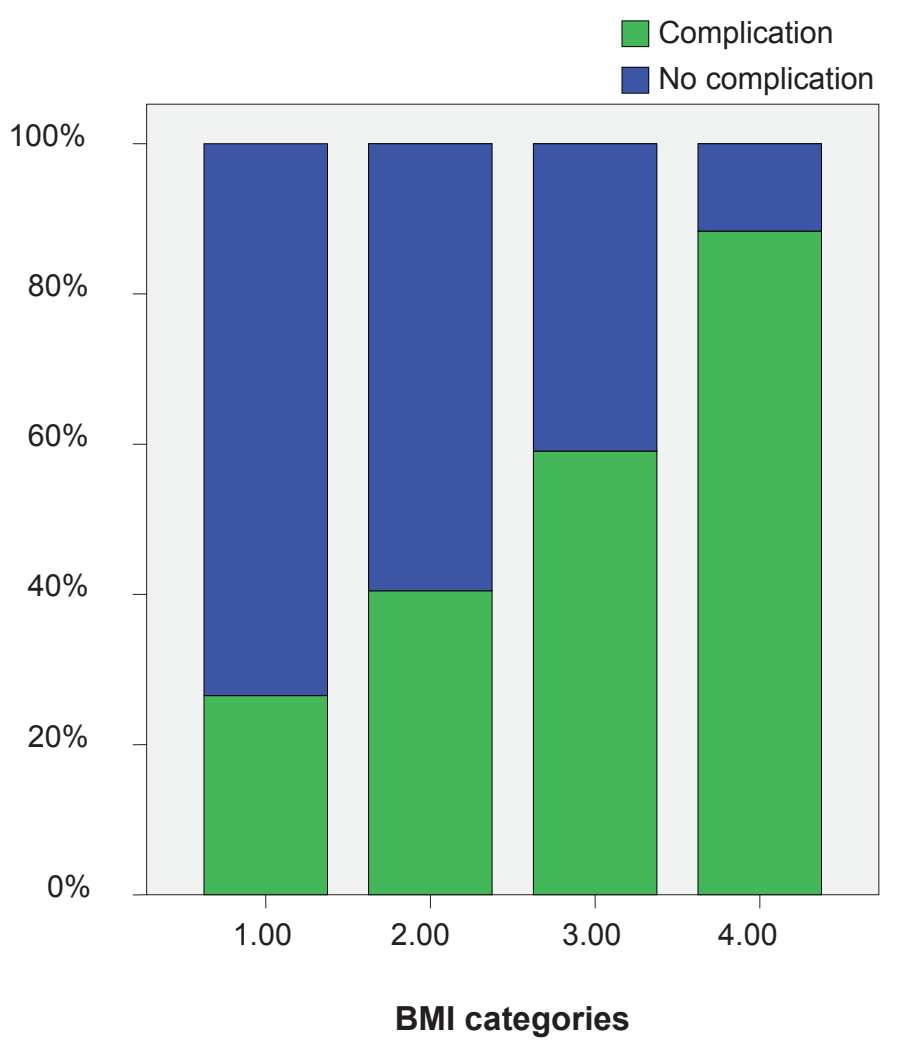

Fig. 1. Percentage of complications per BMI category.

\section{Discussion}

This retrospective study of 43 weight loss surgery patients undergoing body contouring surgery demonstrates that a stable weight over a period of at least 3 months prior to body contouring surgery results in a significant lower complication rate. Furthermore, percentage of excess weight loss prior to body contouring surgery has significant impact on the development of complications. A linear relationship was found between weight status and complication rate. The relative high complication rate was of no influence on patient satisfaction; $67 \%$ of the patients were satisfied or very satisfied with the results of the reconstructive surgery.

The worldwide increase in bariatric surgery over the past decades results in a growing demand for body contouring surgery [15]. In order to optimize the outcome of body contouring surgery, it is mandatory to identify predictors both in terms of complications and patient satisfaction.

The overall complication rate of $27.9 \%$ in the present study is high compared to complication rates in non-obese subjects, but similar to that reported in the literature (20-66\%) [2-5]. Our major complication rate (grade 2 and 3b: $8.8 \%$ ) is relatively low in comparison with that found by Neaman et al. [4] (16\%) and Vastine et al. [3] (13\%), but a comparison with the literature is difficult because of the variety of definitions of minor and major complications $[2-4,6]$. 
Table 6. An overview of risk factors for body contouring surgery in post-bariatric surgery

\begin{tabular}{llll}
\hline Reference & $\begin{array}{l}\text { Number of } \\
\text { subjects }\end{array}$ & Type of study & Risk factors \\
\hline Greco et al. [5] & 222 & retrospective & $\begin{array}{l}\text { ASA classification } \\
\text { \% weight loss }\end{array}$ \\
\hline Au et al. [6] & 129 & retrospective & BMI \\
\hline Hensel et al. [15] & 199 & retrospective & $\begin{array}{l}\text { smoking } \\
\text { DM/HT }\end{array}$ \\
\hline Rogliani et al. [10] & 57 & retrospective & smoking \\
\hline De Kerviler et al. [7] & 104 & retrospective & $\begin{array}{l}\text { BMI } \\
\text { total resection weight }\end{array}$ \\
\hline Arthurs et al. [2] & 126 & retrospective & BMI \\
\hline Neaman et al. [4] & 206 & retrospective & $\begin{array}{l}\text { BMI } \\
\text { amount of removed tissue }\end{array}$ \\
\hline Vastine et al. [3] & 90 & retrospective & BMI \\
\hline Agha-Mohammadi & - & review & $\begin{array}{l}\text { nutritional deficiency } \\
\text { et al. [11] }\end{array}$ \\
\hline Gravante et al. [9] & 60 & prospective & BMI \\
\hline Coon et al. [12] & 449 & prospective & $\begin{array}{l}\text { intra-operation time } \\
\text { multiple procedures } \\
\text { maximum BMI } \\
\text { change (maximum minus current) } \\
\text { in BMI }\end{array}$ \\
\hline & & & \\
\hline
\end{tabular}

Many risk factors for body contouring surgery after massive weight loss have been studied in the literature, but only few are addressed as significant of poor outcome (table 6). In our study, BMI was a significant risk factor for post-operative complications after body contouring surgery, which parallels the findings of other authors [2,6]. Most patients who seek body contouring surgery after weight loss are still overweight, and obesity is a well-known risk factor for complications of surgery in general [16]. Most studies, except for Kroll and Netscher [16], fail to find a linear relationship between BMI and complication rate. Howeever, a cut-off BMI above which the complication rate significantly increases, as found in our study, was also described by others $[4,6,16]$. Patients with a BMI $<30 \mathrm{~kg} / \mathrm{m}^{2}$ experienced significant less complications than patients with a BMI $>30 \mathrm{~kg} / \mathrm{m}^{2}(19.5$ vs. $42.3 \%$; $\mathrm{p}<0.05)$. The percentage of excess weight loss prior to body contouring surgery was an independent predictor for post-operative complications. This is interesting as it emphasizes the importance to strive for a weight close to normal before surgery to minimize the risk of complications. No relationship was found between the maximum weight before bariatric surgery or total weight of resected tissue at body contouring surgery and complications which is in contrast to findings of Coon et al. [12] and Neaman [4].

The most interesting secondary finding of our study was the influence of a stable weight prior to surgery. Patients hav- ing a stable weight plateau for 3 months or longer before body contouring surgery experience significant less complications in comparison to patients with a pre-operative variable weight (19.5 vs. $45.8 \%$ ). Except for Kerviler et al. [7], no author emphasize the importance of a stable weight. An exact explanation for this relationship cannot be given thus far, but one hypothesis is that the nutrition status is better in patients with a stable weight because the body is no longer in a katabolic state. Bariatric surgery may induce nutritional imbalance through malabsorption and intake restriction [17, 18]. This can result in vitamin deficiencies and protein malnourishment, both negatively influencing wound healing. Weight reduction after bariatric surgery plateaus after 12-18 months, and most patients have significant lax and redundant skin,. making body contouring surgery desirable at this time. However, this is also the period during which patients have minimal nutritional reserves, because $50 \%$ of the vitamin and mineral deficiencies occur within the first year [11]. No recovery time for the body has passed at the time of body contouring surgery. Due to their strict selection criteria like a minimum excess body mass index loss $\geq 30 \%$ and long plateau phase of 12 months, de Kerviler at al. [7] did reduce their complication rate from 40 to $26.9 \%$ which support our findings. In a study of Agha-Mohamadi and Hurwitz [11], nutritional supplementation reduced the complication rate from 66 to $18.9 \%$. In which way a stable weight plateau influences the outcome of 
body contouring treatment is not yet clear, but these results emphasize that timing of surgery is of great importance.

As most severe nutritional deficiencies develop after bypass surgery, we expect to see more complications in patients after gastric bypass surgery in comparison to gastric banding. However, we failed to to find such a relationship. Thus, the impact of the surgical treatment applied to achieve weight loss is still unclear $[3,5,19]$. Further studies are necessary among gastric bypass and gastric banding patients to analyze if the surgical procedure applied to achieve weight loss has any effect on the outcome of body contouring interventions.

The present study is a retrospective analysis with its known shortcomings. Not all indicators noted in the literature were analyzed because of missing data. Co-morbidities such as hypertension, diabetes mellitus and cardiovascular disease are generally associated with a high complication rate [4]. As the number of patients with co-morbidities in our study was rather small (14 out of 68 procedures), no firm conclusion could be drawn from our data.

The complication rate did not influence patients satisfaction following body contouring surgery. Patients suffer from lax and redundant skin after massive weight loss which limits physical activity and adversely affects the patient's quality of life [20]. Body contouring surgery should therefore be classified as functional surgery, positively contributing to the longterm results of bariatric surgery.

\section{Conclusion}

A stable weight prior to body contouring surgery in previously morbidly obese patients results in a significant lower complication rate. Furthermore, patients' BMI and percentage of excess weight loss are highly significant risk factors for complications. The positive effects of body contouring surgery on the long-term results of bariatric surgery counterbalance the relatively high complication rate. Careful pre-operative planning and patient selection are essential to optimize the results of body contouring surgery in post-bariatric patients.

\section{Disclosure Statement}

The authors declare no conflicts of interest.

\section{References}

1 Buchwald H, Avidor Y, Braunwald E, Jensen MD, Pories W, Fahrbach K, Schoelles K: Bariatric surgery. A systemic review and meta-analysis. JAMA 2004;14:1724-1737.

- Arthurs ZM, Cuadrado D, Sohn V, Wolcott K, Lesperance K, Carter P, Sebesta J: Post-bariatric panniculectomy; pre-panniculectomy body-mass index impacts the complication profile. Am J Surg 2007;193:567-570.

3 Vastine VL, Morgan RF, Williams GS, Gampper TJ, Drake DB, Knox LK, Lin KY: Wound complications of abdominoplasty in obese patients. Ann Plast Surg 1999;42:34-39.

4 Neaman KC, Hansen JE: Analysis of complications from abdominoplasty. A review of 206 cases at a university hospital. Ann Plast Surg 2007;58:292-298.

$\checkmark 5$ Greco JA, Castaldo ET, Nanney LB Wendel JJ, Summit JB, Kelly KJ, Braun SA, Hagan KF, Shack RB: The effect of weight loss surgery and body mass index on wound complications after abdominal contouring operations. Ann Plast Surg 2008;61: 235-242.

6 Au K, Hazard SW, Dyer A, Boustred AM, Mackay DR, Miraliakbari R: Correlation of complications of body contouring surgery with increasing body mass index. Aesthetic Surg J 2008;28:425-429.

7 De Kerviler S, Husler R, Banic A, Constantinescu MA: Body contouring surgery following bariatric surgery and dietetically induced massive weight reduction; a risk analysis. Obes Surg 2009;19: 553-559.
8 Hensel JM, Lehman JA, Tantri MP, Parker MG, Wagner DS, Topham NS: An outcomes analysis and satisfaction survey of 199 consecutive abdominoplasties. Ann Plast Surg 2001;46:357-363.

$\checkmark$ Gravante G, Araco A, Sorge R, Araco F, Delogu $\mathrm{D}$, Cervelli V: Wound infections in post-bariatric patients undergoing body contouring abdominoplasty : the role of smoking. Obes Surg 2007;17: 1325-1331.

10 Rogliani M, Labardi L, Silvi E, Maggiulli F, Grimaldi M, Cervelli V: Smokers: risks and complications in abdominal dermolipectomy. Aesthetic Plast Surg 2006;30:422-424.

11 Agha-Mohammadi S, Hurwitz D: Potential impacts of nutritional deficiency of post-bariatric patients on body-contouring surgery. Plast Reconstr Surg 2008;122:1901-1914.

12 Coon DB, Gusenoff JA, Kannan NBA, El Khoudary SR, Naghshineh N, Rubin JP: Body mass and surgical complications in the post-bariatric reconstructive patient; analysis of 511 cases. Ann Plast Surg 2009;249:397-401.

13 Dindo D, Demartines N, Clavien P: Classification of surgical complications. A new proposal with evaluation in a cohort of 6336 patients and results of a survey. Ann Surg 2004;240:205-213.
14 Clavien PA, Barkun J, Oliveira ML, Vauthey JN, Dindo D, Schulick RD, de Santibañes E, Pekolj J, Slankamenac K, Bassi C, Graf R, Vonlanthen R, Padbury R, Cameron JL, Makuuchi M: The Clavien-Dindo classification of surgical complications: five-year experience. Ann Surg 2009;250:187-196.

15 American Society of Plastic Surgeons (ASAPS): Body contouring after massive weight loss. $2005 \mathrm{www}$. plasticsurgery.org/media/statistics/2005statistics.cfm.

16 Krol SS, Netscher DT: Complications of TRAM flap breast reconstruction in obese patients. Plast Reconstr Surg 1989;84:886-892.

17 Malinowski SS: Nutritional and metabolic complications of bariatric surgery. Am J Med Sci 2006; 331:219-225.

18 Davies DJ, Baxter JM, Baxter JN: Nutritional deficiencies after bariatric surgery. Obes Surg 2007; 17:1150-1158.

19 Gusenoff JA, Coon D, Rubin JP: Implications of weight loss method in body contouring outcomes. Plast Reconstr Surg 2009;123:373-376.

20 Van der Beek ES, te Riele W, Specken TF, Boerma D, van Ramshorst B: The impact of reconstructive procedures following bariatric surgery on patient well-being and quality of life. Obes Surg 2010;20:36-41. 